\title{
Fostering Quality in Respiratory Therapy Education - A Need of the Hour
}

The respiratory care profession was formally established in India over 25 years ago; concomitantly, numerous training programs were also started in different parts of the country. ${ }^{[1]}$ Even though these programs started simultaneously, the core curriculum varied in its structure and duration between different institutions. Factors that still need attention to ensure Respiratory Therapist's (RT) quality of education and skills include a uniform nomenclature and good curriculum design, providing qualified faculty and adequate resources..$^{[2]}$

\section{The Age of Stagnation}

Changes in the health-care policies and booming of multispecialty tertiary care centers resulted in a breakthrough demand for respiratory therapy and other allied health-care (AHC) professionals in the country. ${ }^{[3]}$ Subsequently, the country witnessed the installation of many academic institutions offering respiratory therapy programs. ${ }^{[1]}$ Majority of them operate without any regulations or control over the quality of education or the number of student intake every year. A statutory authority over the practice of respiratory therapy and a licensing body is not yet in place. This affects the quality of respiratory therapy education along with other AHC professions. ${ }^{[4]}$ Several additional factors also need attention. A good quality teaching model, qualified educators, self-evaluation and review, better working conditions, responsive relationship with the students, collecting and scrutinizing feedback from the stakeholders, and learning outcome assessments are also required ${ }^{[5]}$ Finally, as with many other professions, the "brain drain" phenomenon has resulted in most well-trained RTs leaving the country's shores for greener pastures in other countries. ${ }^{[6]}$

It is our view from the long-lasting experience in the professional organization as present and past office bearers that the respiratory therapists across the country must show more initiative and foresight. The "ideal" model needs to change to provide room for remodelling with the changing times. They need to adapt to changing practices in respiratory care over the years. They should be willing to embrace new ideas or change practices, exchange ideas, review recent literature, and expand the scope of practice to avoid stagnation in professional growth.

A leader must always be ahead of time and have the courage to test new ideas. ${ }^{[7]}$ Many young RTs are pushed into administrators and leaders early in life, which allows them to learn, administer, and bring in new ideas. Even though technically competent, some leaders take on the starring role without the fundamental provisions to do the job well. They must learn to solicit or have access to opportunities to participate in relevant professional learning and improvement. ${ }^{[7]}$ Respiratory Therapy in India, as a profession, is at a critical juncture; opportunities have arisen and it is time for the RTs to transform drastically at this time. There is a real prospect to see the profession in India reach great heights.

\section{Hope and Progress}

If we need respiratory care to be a relevant and esteemed health-care profession, it is essential to establish entry-level academic credentials. ${ }^{[8]}$ Respiratory therapy in India is a relatively new and fast-growing speciality. There is a surge in the number of universities and academic institutions offering the respiratory therapy program; at this bourgeoning phase, it would be essential to regulate the course curriculum, the available facilities, the teachers and the number of registered candidates. Only then would we be able to see dignified, respectable, and reliant RTs in the country in the future. Furthermore, the current leadership, especially those who run an academic program, are duty-bound to establish a demarcated organizational structure within their institution that is expected to accommodate continuous quality improvement. ${ }^{[9]}$

The Government of India has introduced the newly constituted National Commission for Allied and Health Care Professions (NCAHCP) bill 2020 to rationalize the country's Allied Health Care profession and bring more opportunities for the respiratory therapy profession. ${ }^{[10]}$ The long-term dream of the Indian Association of Respiratory Care (IARC) and the Respiratory Therapists of India has finally borne fruit. The Society now has an enhanced responsibility in the development and organization of respiratory therapy practice and education in the country. ${ }^{[11]}$ The recently established Indian Academy of Respiratory Care, under the auspices of IARC as its academic wing, has a substantial role in defining the professional practice guidelines and curriculum development, emphasizing interactive and clinically integrated teaching strategies. ${ }^{[12]} \mathrm{A}$ significant challenge that the Society envisages is unifying the contents of the curriculum for the entire country. IARC should also seize the opportunity offered by the NCAHCP bill to bring the various respiratory therapy courses conducted under different nomenclatures under a single umbrella.

A large group of expert clinicians and the public in our country may not have heard of a respiratory therapist until the pandemic. However, they have been an integral member of the multi-disciplinary health-care team for years. As the number of patients with COVID-19 has grown, so has the demand for RT's more than ever before. ${ }^{[13,14]}$ The role of an RT might be challenging and stressful; their role would have 
been reverberated as challenging well before the pandemic and, it has now turned out to be multifaceted. Considering the challenging involvement of the RTs at all levels of patient care, they will have a major role in the future of health-care services in our country.

RT's scope of practice will increase exponentially when the Indian Government's idea of establishing small-scale intensive-care settings in rural areas and advanced home care/long-term care facilities are implemented. ${ }^{[15]}$ To participate optimally in these processes, RT's roles, knowledge, competencies, and practices need to be renewed and reformed to innovative clinical and management norms. ${ }^{[16]}$ Academic institutions and government authorities must take the initiative to rationalize the need for establishing quality measures in respiratory therapy education and $\mathrm{AHC}$ as a whole..$^{[5]} \mathrm{It}$ is the need of the hour to find the gaps in AHC education, the scope of practice, and its alignment with the current work structure. ${ }^{[17]}$ There is, therefore, a clear need to rationalize the investments made by the Government and various organizations in the deployment of resources and structures in respiratory therapy and AHC education, strategies adopted for the making of information about quality measures, desirable performance indicators, and the stakeholder's awareness of these policies.

Jithin K. Sreedharan, Suresh G. Nair ${ }^{1}$

Lecturer, Department of Respiratory Care, Prince Sultan Military College of Health Sciences, Dhahran, Saudi Arabia, Srinivas Institute of Medical Sciences, Srinivas University, Mangalore, 'Lead Consultant, Anaesthesia and Critical Care, Aster Medcity, Kochi, Kerala, India

Address for correspondence: Mr. Jithin K. Sreedharan, Lecturer in Respiratory Therapy, Prince Sultan Military College of Health Sciences, Dhahran, Saudi Arabia. E-mail: jithinksree@pcmchs.edu.sa

\section{REFERENCES}

1. Sreedharan JK, Varghese S. Twenty-five years of excellence; respiratory therapy in India - past, present, and future. Indian J Respir Care 2020;9:5-11.

2. Shevade MS, Yeravdekar RC, Salvi SS. A cross-sectional survey of practice patterns and selected demographics of respiratory therapists in India. Respir Care 2021;66:66-72.

3. Health Sector Council, National Qualification Register; Occupational Mapping Report: Allied Health and Paramedic Sector. Available from: $\quad$ https://nqr.gov.in/sites/default/files/Annexure $\% 202-\% 20$ Occupational\%20Mapping\%20Report\%20v280313.pdf. [Last accessed on 2021 Apr 22].

4. Gaur V. An overview of redefining paradigm: India's allied health professional. Int J Biochem 2018;1:20-34.

5. Viewpoint: The Status of Allied Health Professionals in India: Need for a SWOT Analysis. Available from: https://amity.edu/UserFiles/admaa/ dc27ePaper\%205.pdf. [Last accessed on 2021 Apr 22].

6. Misau YA, Al-Sadat N, Gerei AB. Brain-drain and health care delivery in developing countries. J Public Health Afr 2010;1:e6.
7. Venkateswaran R. Importance of uniformity in education, continuing education and preparing tomorrow's leaders. Indian J Respir Care 2012;1:11-4.

8. Barnes TA, Kacmarek RM, Kageler WV, Morris MJ, Durbin CG Jr. Transitioning the respiratory therapy workforce for 2015 and beyond. Respir Care 2011;56:681-90.

9. Parker AM, Liu X, Harris AD, Shanholtz CB, Smith RL, Hess DR, et al. Respiratory therapy organizational changes are associated with increased respiratory care utilization. Respir Care 2013;58:438-49.

10. Ministry of Health, Family Welfare, Government of India. The National Commission for Allied and Healthcare Professions Bill, 2020. Ministry of Health and Family Welfare, Government of India. Available from: https://prsindia.org/billtrack/the-national-commission-for-allied-and-he althcare-professions-bill-2020. [Last accessed on 2021 Apr 14].

11. Kamalakannan S, Chockalingam $M$. The national commission for allied and health care professions bill 2020: Implications for occupational therapists and the AIOTA. Indian J Occup Ther 202;52:104.

12. The Indian Association of Respiratory Care (IARC). News Update: IARC Announces the Expansion of its Academic Wing, Indian Academy of Respiratory Care. Available from: https://iarc.in/iarc/ newsDetails/8. [Last accessed on 2021 Apr 04].

13. Sawadkar MM, Nayak VR. Respiratory therapists: The unnoticed warriors during COVID-19 pandemic in India. Can J Respir Ther 2020;56:57.

14. Rajan A, Reddy M, Todur P, Johnson S. Knowledge, confidence, and perception of respiratory therapists as frontliners in managing COVID-19 cases - A questionnaire survey. Indian J Respir Care 2021;10:93-9.

15. Rickards T, Kitts E. The roles, they are a changing: Respiratory therapists as part of the multidisciplinary, community, primary health care team. Can J Respir Ther 2018;54:83-5.

16. Kacmarek RM, Durbin CG, Barnes TA, Kageler WV, Walton JR, O'Neil EH. Creating a vision for respiratory care in 2015 and beyond. Respir Care 2009;54:375-89.

17. Rawekar A, Gotarkar S, Patond S, Dakhode S. Challenges of allied healthcare professionals in India - Establishing the council is need of the hour. Indian J Forensic Med Toxicol 2020;14:4.

This is an open access journal, and articles are distributed under the terms of the Creative Commons Attribution-NonCommercial-ShareAlike 4.0 License, which allows others to remix, tweak, and build upon the work non-commercially, as long as appropriate credit is given and the new creations are licensed under the identical terms.

\begin{tabular}{|l|l|}
\hline \multicolumn{3}{|c|}{ Access this article online } \\
\hline Quick Response Code: & Website: \\
\hline
\end{tabular}

How to cite this article: Sreedharan JK, Nair SG. Fostering quality in respiratory therapy education - A need of the hour. Indian J Respir Care 2021;10:167-8.

Received: $19-04-2021$

Accepted: $28-04-2021$
Revised: 22-04-2021 Published: 14-06-2021 